\title{
Crystallization of organically templated phosphomolybdate cluster-based solids from aqueous solution
}

\author{
MINAKSHI ASNANI, DINESH KUMAR, T DURAISAMY \\ and ARUNACHALAM RAMANAN* \\ Department of Chemistry, Indian Institute of Technology Delhi, New Delhi 110016, India \\ e-mail: aramanan@chemistry.iitd.ac.in
}

\begin{abstract}
The paper reports the synthesis and structural characterization of several organic-inorganic solids involving phosphomolybdate clusters. The Strandberg-type $\left\{\mathrm{P}_{2} \mathrm{Mo}_{5}^{\mathrm{VI}} \mathrm{O}_{23}\right\}$ and the lower-valent $\left\{\mathrm{P}_{4} \mathrm{Mo}_{6}^{\mathrm{V}} \mathrm{O}_{31}\right\}$ cluster based solids were isolated in the presence of en (ethylenediamine) by controlling $\mathrm{pH}$ of the reaction medium. The lower-valent cluster invariably requires the presence of a suitable metal cation for further stabilization. A detailed investigation of the system was carried out where three different weak acids viz. oxalic acid, succinic acid and glycine were used in the entire $\mathrm{pH}$ range (1-12). Our results establish that the organic amine (en) is alone capable of reducing the molybdenum core in the absence of an organic acid at a suitable $\mathrm{pH}$. Hence, $\mathrm{pH}$ of the reaction medium combined with suitable temperature favours the formation of lower-valent phosphomolybdate cluster. Higher $\mathrm{pH}$ favours the precipitation of a new sodium hydrogen phosphate.
\end{abstract}

Keywords. Phosphomolybdate cluster; supramolecular interaction; hydrothermal synthesis.

\section{Introduction}

Polyoxomolybdate (POM) clusters are attractive nanosized molecular building blocks for the formation of multi-dimensional organic-inorganic hybrid networks. ${ }^{1-4}$ It is always intriguing why multi-component crystals based on phosphomolybdate clusters such as Strandberg-type anion, ${ }^{5}\left(\mathrm{P}_{2} \mathrm{Mo}_{5} \mathrm{O}_{23}\right)$, Wells-Dawson anion, ${ }^{6,7}\left(\mathrm{P}_{2} \mathrm{Mo}_{18} \mathrm{O}_{62}\right)$ and Keggin, ${ }^{8-10}\left(\mathrm{PMo}_{12} \mathrm{O}_{40}\right)$ precipitate with selected counter cations. The counter cations may vary from simple metal ions $(\mathrm{Na}, \mathrm{K}, \mathrm{Cu})$ and metal complexes to varying shapes and sizes of organic cations. Like any other solids, these crystals can also show variable stoichiometry $\left(\mathrm{A}_{\mathrm{m}} \mathrm{X}_{\mathrm{n}}\right.$ where, $\mathrm{m}$ and $\mathrm{n}$ are integers) and occur frequently as hydrates of which a few show interesting water oligomers. A common question often raised is whether these are stable crystals that represent free energy minima in the structural landscape of a particular system or non-equilibrium phases. The energy of $A_{m} X_{n}$ can be minimized due to either enthalpic or entropic reasons. Enthalpic driven multi-component crystals are generally characterized by distinctive intermolecular interactions like hydrogen bonding. While hydrogen bonds are dominant directive forces in assembling organic cations and POM anions, metal-oxygen coordination is another distinct force in crystallizing metal or metal complex derived polyoxomolybdates. In recent years, weak organic bases and

*For correspondence acids are commonly employed as structure directors or templates to control the multi-dimensional frameworks of POM-based solids. The interest mainly stems from the fact that a few of these structurally diverse solids are potential catalysts and proton conductors. ${ }^{11}$ Apart from the apparent electrostatic factors, non-covalent interactions operating between the organic cations and inorganic anions contribute significantly to the structural diversity of these solids. ${ }^{5}$ In the context of crystal engineering, lately there is considerable interest to rationalize the occurrence of multiple forms (polymorphs, pseudopolymorphs, hydrates/solvates, salts, coordination polymers, etc.) for a crystal obtained from a set of reacting molecules. ${ }^{12}$ Formation of a crystalline substance should not be represented by a simple equation as crystallization is a supramolecular reaction. ${ }^{13} \mathrm{We}$ could employ retrosynthesis, ${ }^{14}$ the crystal engineering tool to postulate the possible ways in which tectons or chemically reasonable molecules ${ }^{15}$ supramolecularly aggregate before the onset of nucleation by analysing several related crystal structures. Such a hypothesis can provide chemical insights into the occurrence of a particular form. The composition or stoichiometry of the resulting solid, the occurrence of hydration, structural features like water clustering, helicity, etc. may thus become obvious as the mechanistic pathway suggest a link between molecules interacting in the reactant phase and the intermolecular interactions observable in the solid state. In other words, we can make a reasonable assessment of structure-synthesis correlation. 
Our group has successfully employed this approach in several studies. ${ }^{16}$

We have been systematically analysing the crystallization of organic-inorganic salts obtained in the multinary system organic amine $-\left\{\mathrm{P}_{2} \mathrm{Mo}_{5} \mathrm{O}_{23}\right\}-\mathrm{H}_{2} \mathrm{O}$ and perform structure-synthesis correlation using retrosynthesis. The Strandebrg's cluster $\left\{\mathrm{P}_{2} \mathrm{Mo}_{5} \mathrm{O}_{23}\right\}$ (henceforth referred to as $P_{2} M o_{5}$ ) is reasonably a stable cluster anion occurring in situ in aqueous solution when a soluble molybdate source is acidified with phosphoric acid over a wide range of $\mathrm{pH}$. Our experience suggests that phosphate to molybdenum molar ratio is hardly a factor to stabilize a particular cluster. A number of salts based on $\mathrm{P}_{2} \mathrm{Mo}_{5}$ as building blocks is reported in the literature, ${ }^{17}$ however, we were the first one to investigate the influence of non-bonding interactions between the organic cations and the Strandberg anion and its influence in the occurrence of water oligomers. ${ }^{5}$ In selected cases, we also observed the formation of a reduced phosphomolybdate cluster of the composition $\left(\mathrm{P}_{4} \mathrm{Mo}_{6}^{\mathrm{V}} \mathrm{O}_{31}\right)$ forming as a competitive phase at higher temperatures under hydrothermal condition. A combination of organic base that can undergo oxidation and temperature favours the reduction of molybdenum (VI) to lower valent molybdenum $(\mathrm{V})$ species which in turn led to the formation of the reduced phosphomolybdates. Unlike the Strandberg's cluster, this cluster requires further stabilization by a suitable metal ion like $\mathrm{Na}, \mathrm{Cu}$, etc. We report here the formation and crystal structures of five Strandberg cluster based salts and four molybdenum (V) based phosphomolybdate solid isolated from the system phosphomolybdate - organic amine - water. A structure-synthesis correlation is attempted based on a tectonic approach.

\section{Experimental}

\subsection{Synthesis under ambient condition}

Crystallization of multi-component crystals based on POM was attempted from aqueous solution containing a soluble molybdenum source (sodium or ammonium molybdate) and acidified with a weak acid.

2.1a Synthesis of 1: In a typical synthesis $\mathrm{MoO}_{3}$ $(0.5 \mathrm{~g}, 3.5 \mathrm{mmol})$ was dissolved in morpholine $(2.3 \mathrm{~mL}$, $3.5 \mathrm{mmol})$ in $60 \mathrm{~mL}$ of distilled water. $\mathrm{H}_{3} \mathrm{PO}_{4}(0.8 \mathrm{~mL}$, $4.0 \mathrm{mmol}$ ) was then added to the resulting grey colour solution to adjust the $\mathrm{pH}$ to $\sim 4.0$ and was kept at room temperature $\left(25^{\circ} \mathrm{C}\right)$ for three months for crystallization. Colourless needle-like crystals were filtered off from the solution and washed with water followed by acetone and dried in air. Yield: $1.2 \mathrm{~g}, 70 \%$ based on molybdenum. Elemental analysis for 1: C, $3.0 ; \mathrm{H}, 1.0 ; \mathrm{N}, 2.0 \%$ (Found) and C, 3.2; H,1.0; N,1.8\% (Calcd.).

2.1b Synthesis of 2: A mixture of $\mathrm{Na}_{2} \mathrm{MoO}_{4} \cdot 2 \mathrm{H}_{2} \mathrm{O}$ $(0.5 \mathrm{~g}, 2.1 \mathrm{mmol})$ and hexamethylenetetramine (HMTA) $(0.453 \mathrm{~g}, 3.1 \mathrm{mmol})$ and $60 \mathrm{~mL}$ of water were taken in a $150 \mathrm{~mL}$ beaker. The $\mathrm{pH}$ of the colourless clear solution was adjusted to 4.2 by the addition of $\mathrm{H}_{3} \mathrm{PO}_{4}(0.4 \mathrm{~mL}$, $2.0 \mathrm{mmol}$ ). The resulting light brown solution was kept at room temperature $\left(25^{\circ} \mathrm{C}\right)$ for two months; colourless crystals were filtered off and washed with water and acetone. Yield: $2.2 \mathrm{~g}, 65 \%$ based on molybdenum. Elemental analysis for 2: C, 5.6; H, 1.0; N, 3.9\% (Found) and $\mathrm{C}, 6.0 ; \mathrm{H}, 1.0 ; \mathrm{N}, 4.0 \%$ (Calcd).

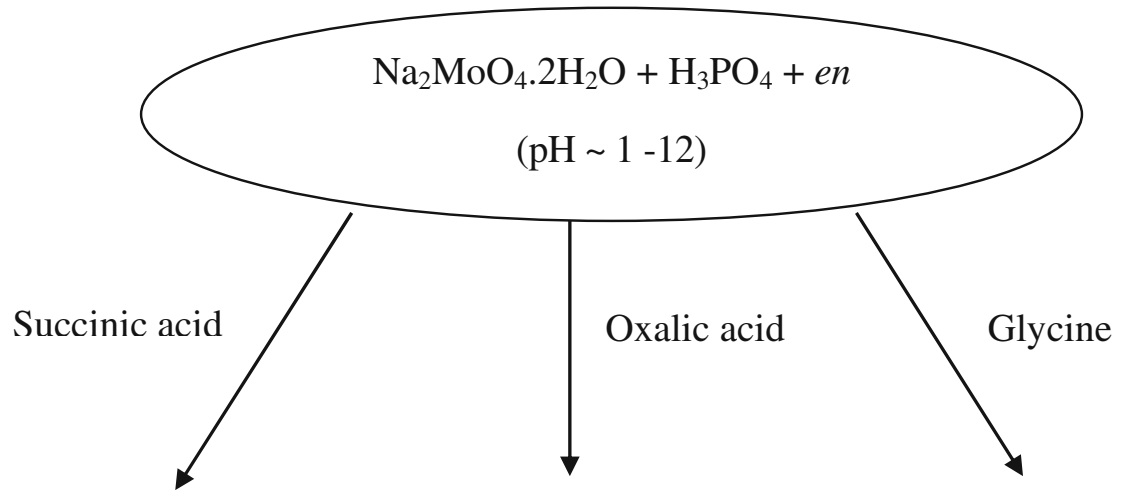
Mixed phase containing
$\mathrm{Na}\left(\mathrm{Mo}_{6}{ }^{\mathrm{V}} \mathrm{P}_{4} \mathrm{O}_{31}\right)_{2}$ obtained
Single phase $\mathrm{Mo}_{6}{ }^{\mathrm{V}} \mathrm{P}_{4} \mathrm{O}_{31}$
Single phase $\mathrm{Mo}_{6}{ }^{\mathrm{V}} \mathrm{P}_{4} \mathrm{O}_{31}$ obtained at $\mathrm{pH} 7$ obtained at $\mathrm{pH} 1-9$
between $\mathrm{pH} 1-12$

Scheme 1. Schematic representation of synthetic strategy employed. 
2.1c Synthesis of 3-10: We later employed ethylenediamine as a template. Oxalic or succinic acids were preferred over acetic acid. Also, at higher $\mathrm{pH}$, glycine was preferred. In a typical synthesis, $\mathrm{Na}_{2} \mathrm{MoO}_{4} \cdot 2 \mathrm{H}_{2} \mathrm{O}$ $(0.6217 \mathrm{~g}, 2.57 \mathrm{mmol})$, en $(0.2 \mathrm{~mL}, 3.22 \mathrm{mmol})$ and organic template \{oxalic acid, succinic acid and an amino acid, glycine $(0.6215 \mathrm{~g}, 4.93 \mathrm{mmol})\}$ were taken in a molar ratio $1: 1.25: 2$ in $15 \mathrm{~mL}$ of $\mathrm{H}_{2} \mathrm{O}$ in a teflon lined stainless steel container. Adequate amount of $\mathrm{H}_{3} \mathrm{PO}_{4}$ (1M) was added to this reaction to provide phosphate source and to adjust $\mathrm{pH}$. The reactants were

\section{Organic template}

Succinic acid $+e n$

Oxalic acid $+e n$

Glycine + en heated at $150^{\circ} \mathrm{C}$ for two days and then cooled to room temperature. The product obtained was filtered, washed with distilled water followed by acetone and dried in air. Effect of $\mathrm{pH}$ and organic acid on the formation of various structures was also investigated extensively.

We varied the stoichiometries of molybdenum source and the counter organic (organic base) with an objective to obtain crystalline products. At times, good crystals were obtained only after several days or weeks. Instantaneous precipitation by rapid evaporation invariably led to X-ray amorphous products or multiphasic mixtures.

\section{$p H$ variation}

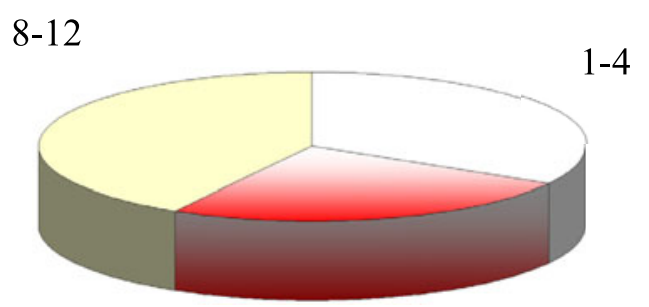

$5-7$

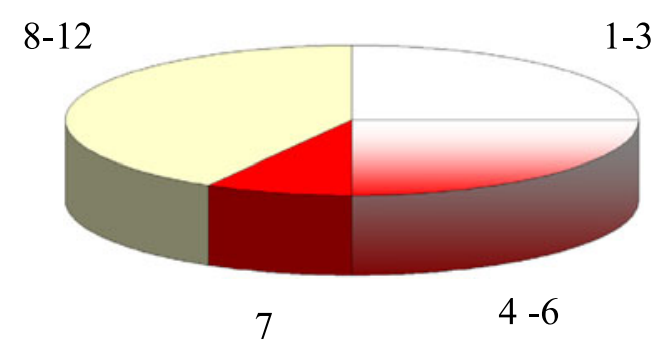

$8-12$

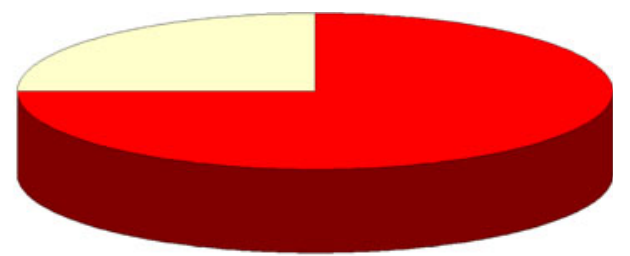

$1-9$

Red crystals $\quad \mathrm{NaHPO}_{4}$

$$
\left\{\mathrm{P}_{2} \mathrm{Mo}_{5}\right\} \quad\left\{\mathrm{Na}\left(\mathrm{P}_{4} \mathrm{Mo}_{6}\right)_{2}\right\}+\left\{\mathrm{P}_{2} \mathrm{Mo}_{5}\right\} \quad\left\{\mathrm{Na}\left(\mathrm{P}_{4} \mathrm{Mo}_{6}\right)_{2}\right\}
$$

Scheme 2. Influence of different organic templates at varying $\mathrm{pH}$. 
Table 1. Crystallographic data for solids 1-5.

\begin{tabular}{|c|c|c|c|c|c|}
\hline & 1 & 2 & 3 & 4 & 5 \\
\hline Empirical formula & $\begin{array}{c}\mathrm{C}_{20} \mathrm{H}_{60} \mathrm{Mo}_{5} \\
\mathrm{~N}_{5} \mathrm{O}_{33} \mathrm{P}_{2}\end{array}$ & $\begin{array}{c}\mathrm{C}_{14} \mathrm{H}_{44} \mathrm{Mo}_{5} \\
\mathrm{~N}_{8} \mathrm{O}_{29} \mathrm{P}_{2}\end{array}$ & $\begin{array}{r}\mathrm{Mo}_{5} \mathrm{P}_{2} \mathrm{O}_{23} \\
\mathrm{C}_{4} \mathrm{~N}_{4} \mathrm{H}_{22}\end{array}$ & $\begin{array}{r}\mathrm{Mo}_{5} \mathrm{P}_{2} \mathrm{O}_{32} \\
\mathrm{C}_{5} \mathrm{~N}_{5} \mathrm{H}_{59}\end{array}$ & $\begin{array}{l}\mathrm{Mo}_{5} \mathrm{P}_{2} \mathrm{O}_{26} \\
\mathrm{C}_{12} \mathrm{~N}_{12} \mathrm{H}_{64}\end{array}$ \\
\hline Formula weight & 1430.29 & 1328.20 & 1035.90 & 2271.86 & 1119.81 \\
\hline Temperature (K) & 298(2) & $298(2)$ & $298(2)$ & $298(2)$ & $298(2)$ \\
\hline Space group & $P 2_{1}$ & $P \overline{1}$ & $C 2 / c$ & $P 2_{1} / c$ & $P \overline{1}$ \\
\hline$a(\AA)$ & $14.1882(2)$ & $12.1142(2)$ & $17.609(3)$ & $13.8369(9)$ & $8.9537(7)$ \\
\hline$b(\AA)$ & $8.4175(1)$ & $13.2522(2)$ & $9.9742(13)$ & $34.482(2)$ & $10.6146(8)$ \\
\hline$c(\AA)$ & $18.7080(1)$ & $14.9194(2)$ & $13.7422(17)$ & $12.8923(8)$ & $17.4236(14)$ \\
\hline$\alpha\left(^{\circ}\right)$ & 90.00 & $89.761(1)$ & 90.00 & 90.00 & $78.77(0)$ \\
\hline$\beta\left(^{\circ}\right)$ & $90.285(1)$ & $77.245(1)$ & $96.826(3)$ & 101.803(1) & $92.713(2)$ \\
\hline$\gamma\left({ }^{\circ}\right)$ & 90.00 & 64.291(1) & 90.00 & 90.00 & $67.32(0)$ \\
\hline $\mathrm{V}\left(\AA^{3}\right)$ & $2234.25(4)$ & 2093.34(3) & 2396.6(6) & $6021.1(7)$ & $1490.31(20)$ \\
\hline $\mathrm{Z}$ & 2 & 2 & 4 & 4 & 1 \\
\hline $\mathrm{D}_{\text {calc }},\left(\mathrm{g} \mathrm{cm}^{-3}\right)$ & 2.126 & 2.107 & 2.871 & 2.506 & 2.651 \\
\hline $\begin{array}{l}\text { Goodness-of-fit } \\
\text { (GOF) on } F^{2}\end{array}$ & 1.023 & 1.085 & 1.105 & 1.010 & 1.169 \\
\hline$\lambda(\AA)$ & 0.71073 & 0.71073 & 0.71073 & 0.71073 & 0.71073 \\
\hline $\mathrm{R}_{1}, w \mathrm{R}_{2}[\mathrm{I}>2 \sigma(I)]^{\mathrm{a}}$ & $0.0259,0.0685$ & $0.0308,0.0924$ & $0.0294,0.0771$ & $0.0441,0.0965$ & $0.0397,0.1067$ \\
\hline $\begin{array}{l}\Delta \rho_{\max } \text { and } \\
\Delta \rho_{\min }\left(\mathrm{e} \AA^{-3}\right)\end{array}$ & 0.631 and -0.674 & - & 0.772 and -1.573 & 1.065 and -0.935 & 0.923 and -0.909 \\
\hline CCDC & 229195 & - & 863392 & 863393 & 863391 \\
\hline
\end{tabular}

Yields vary between 30 and $60 \%$ in most of the studies based on molybdenum. Schemes 1 and 2 briefly describe the synthetic protocol employed and influence of different organic templates at varying $\mathrm{pH}$ in this study.

\section{$2.2 X$-ray crystallographic studies}

X-ray diffraction study of a crystal mounted on a capillary was carried out on a BRUKER AXS SMARTAPEX diffractometer with a CCD area detector $(\mathrm{K} \alpha$ :

Table 2. Crystallographic data for solids 6-10.

\begin{tabular}{|c|c|c|c|c|c|}
\hline & 6 & 7 & 8 & 9 & 10 \\
\hline Empirical formula & $\begin{array}{l}\mathrm{Mo}_{6} \mathrm{P}_{4} \mathrm{O}_{43} \\
\mathrm{Na}_{1} \mathrm{C}_{14} \mathrm{~N}_{14} \mathrm{H}_{93}\end{array}$ & $\begin{array}{l}\mathrm{Mo}_{12} \mathrm{P}_{8} \mathrm{O}_{67} \\
\quad \mathrm{Na}_{2} \mathrm{C}_{12} \mathrm{~N}_{12} \mathrm{H}_{80}\end{array}$ & $\begin{array}{l}\mathrm{Mo}_{6} \mathrm{P}_{4} \mathrm{O}_{39} \\
\mathrm{Na}_{1} \mathrm{C}_{14} \mathrm{~N}_{14} \mathrm{H}_{87}\end{array}$ & $\begin{array}{l}\mathrm{Mo}_{6} \mathrm{P}_{4} \mathrm{O}_{49} \\
\mathrm{Na}_{1} \mathrm{C}_{4} \mathrm{~N}_{4} \mathrm{H}_{116}\end{array}$ & $\begin{array}{c}\mathrm{Na}_{2} \mathrm{P}_{2} \mathrm{O}_{14} \\
\mathrm{C}_{2} \mathrm{~N}_{2} \mathrm{H}_{17}\end{array}$ \\
\hline Formula weight & 2606.03 & 2829.26 & 1483.02 & 3232.28 & 415.08 \\
\hline Temperature(K) & 298(2) & $298(2)$ & $298(2)$ & $298(2)$ & 298(2) \\
\hline Space group & $P 2_{1}$ & $P \overline{1}$ & $P \overline{1}$ & $P 4 /$ ncc & $P 2_{1} / \mathrm{c}$ \\
\hline$a(\AA)$ & $13.223(3)$ & $12.0528(7)$ & $11.7833(11)$ & $27.1919(7)$ & $11.739(3)$ \\
\hline$b(\AA)$ & $16.612(4)$ & $14.6366(9)$ & $13.3689(12)$ & $27.1919(7)$ & $10.193(2)$ \\
\hline$c(\AA)$ & $18.867(5)$ & $21.3482(13)$ & $14.5752(13)$ & $28.2835(10)$ & $6.8574(15)$ \\
\hline$\alpha\left(^{\circ}\right)$ & 90.00 & $80.6570(10)$ & $68.548(2)$ & 90.00 & 90.00 \\
\hline$\beta\left(^{\circ}\right)$ & $96.574(5)$ & $82.6650(10)$ & $74.5030(10)$ & 90.00 & $105.071(3)$ \\
\hline$\gamma\left({ }^{\circ}\right)$ & 90.00 & $76.3050(10)$ & $65.772(2)$ & 90.00 & 90.00 \\
\hline$V\left(\AA^{3}\right)$ & $4117.2(18)$ & $3594.8(4)$ & $1930.1(3)$ & $20912.8(11)$ & $792.3(3)$ \\
\hline $\mathrm{Z}$ & 2 & 2 & 2 & 8 & 4 \\
\hline $\mathrm{D}_{\text {calc }},\left(\mathrm{g} \mathrm{cm}^{-3}\right)$ & 2.102 & 2.614 & 2.552 & 2.053 & 1.719 \\
\hline $\begin{array}{l}\text { Goodness-of-fit } \\
\text { (GOF) on } F^{2}\end{array}$ & 1.025 & 1.039 & 0.978 & 1.038 & 1.096 \\
\hline$\lambda(\AA)$ & 0.71073 & 0.71073 & 0.71073 & 0.71073 & 0.71073 \\
\hline $\mathrm{R}_{1}, w \mathrm{R}_{2}[\mathrm{I}>2 \sigma(I)]^{\mathrm{a}}$ & $0.1009,0.2623$ & $0.0391,0.1134$ & $0.0439,0.1081$ & $0.0606-0.1891$ & $0.0412,0.1081$ \\
\hline $\begin{array}{l}\Delta \rho_{\max } \text { and } \\
\Delta \rho_{\min }\left(\mathrm{e} \AA^{-3}\right)\end{array}$ & 0.923 and -0.909 & 2.134 and -2.024 & 1.307 and -1.373 & 2.513 and -1.571 & 0.538 and -0.276 \\
\hline CCDC & 863395 & 863394 & 863396 & 863397 & 864249 \\
\hline
\end{tabular}




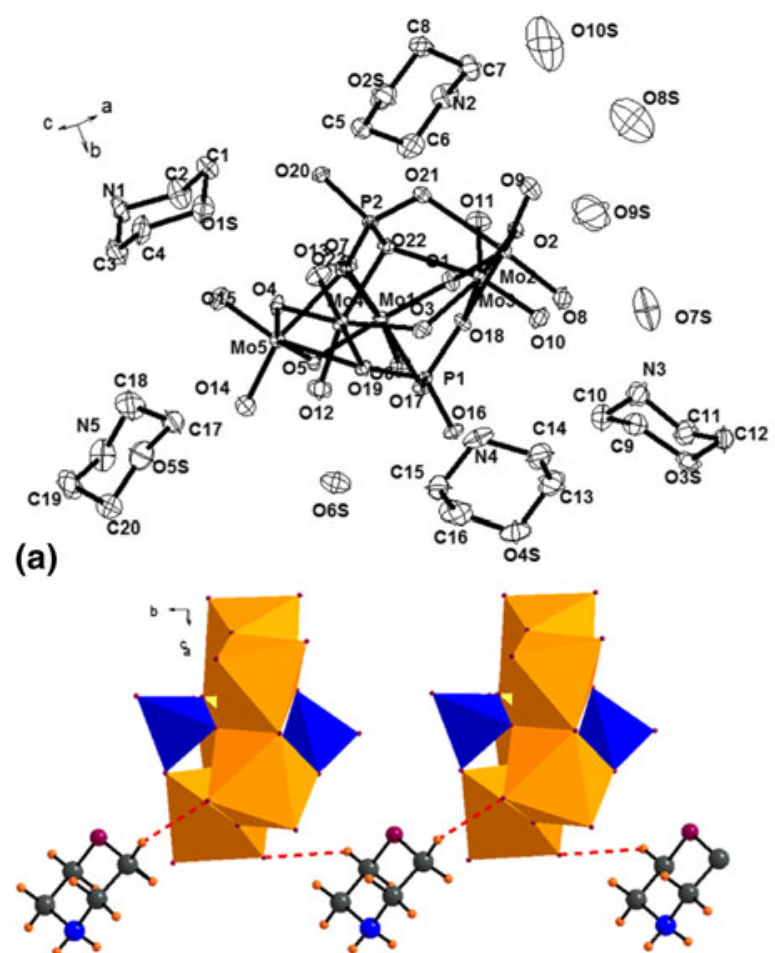

(c)

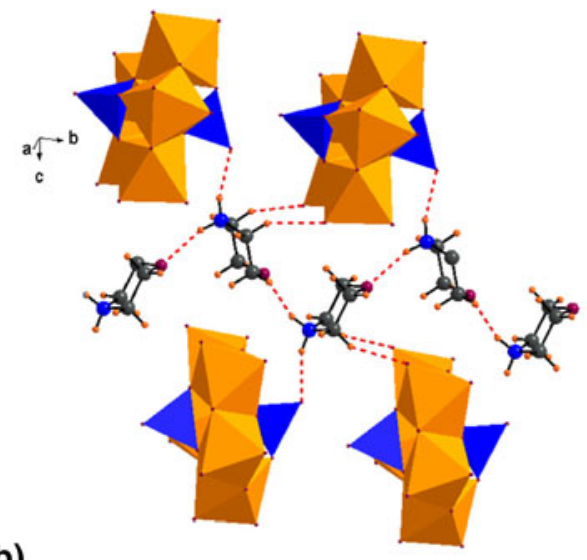

(b)

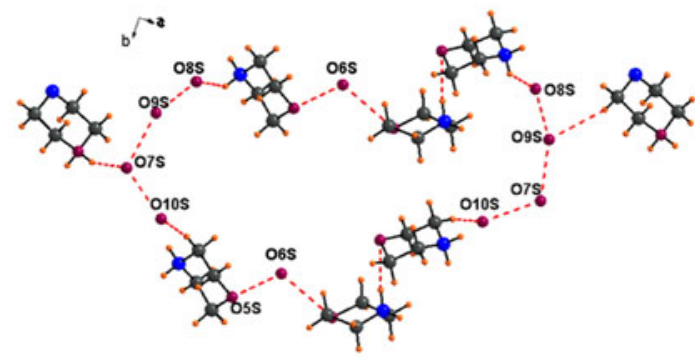

(d)

Figure 1. (a) ORTEP view of asymmetric unit of solid 1. Thermal ellipsoids are drawn at 50\% probability level. (b) Zig-zag arrangement of morpholinium cations with cluster. (c) 1-D chain of cluster with counter cation as morpholinium ions. (d) There is appreciable hydrogen bonding only between the morpholinium ions and the space filling water molecules.

$0.71073 \AA$, monochromator: graphite). ${ }^{18}$ Frames were collected at $\mathrm{T}=298 \mathrm{~K}$ by $\omega, \phi$ and $2 \theta$-rotation at $10 \mathrm{~s}$ per frame with SAINT. ${ }^{19}$ The measured intensities were reduced to $F^{2}$ and corrected for absorption with SADABS. ${ }^{19}$ Structure solution, refinement, and data output were carried out with the SHELXTL program. ${ }^{20}$ Non-hydrogen atoms were refined anisotropically. C$\mathrm{H}$ hydrogen atoms were placed in geometrically calculated positions by using a riding model. O-H hydrogen atoms were localized by difference Fourier maps and refined in subsequent refinement cycles. Images were created with the DIAMOND program. ${ }^{21}$ Hydrogen bonding interactions in the crystal lattice were calculated with SHELXTL and DIAMOND. ${ }^{20,21}$ The crystal data and structure refinement of solids 1-5 and 6-10 are summarized in tables 1 and 2 , respectively.

\section{Results and discussion}

\subsection{Crystal structures of monoamine derived $\mathrm{HP}_{2} \mathrm{Mo}_{5}$ solids (1 and $\left.\mathbf{2}\right)$}

The crystal structure of $\mathbf{1},\left[\left(\mathrm{C}_{4} \mathrm{H}_{10} \mathrm{NO}\right)_{5}\right]\left[\mathrm{HP}_{2} \mathrm{Mo}_{5} \mathrm{O}_{23}\right]$. $5 \mathrm{H}_{2} \mathrm{O}$, is made of monoprotonated cluster $\mathrm{HP} \mathrm{P}_{2} \mathrm{Mo}_{5}$ and morpholinium cations. $\mathrm{N}-\mathrm{H} \cdot \cdots \mathrm{O}$ and $\mathrm{C}-\mathrm{H} \cdot \cdots \mathrm{O}$ interactions (supplementary table S1) aggregate the cations and anions on a sheet (figure 1). The structure also shows strong interactions between the organic cations and mediating water molecules as observed in our earlier study. ${ }^{5}$

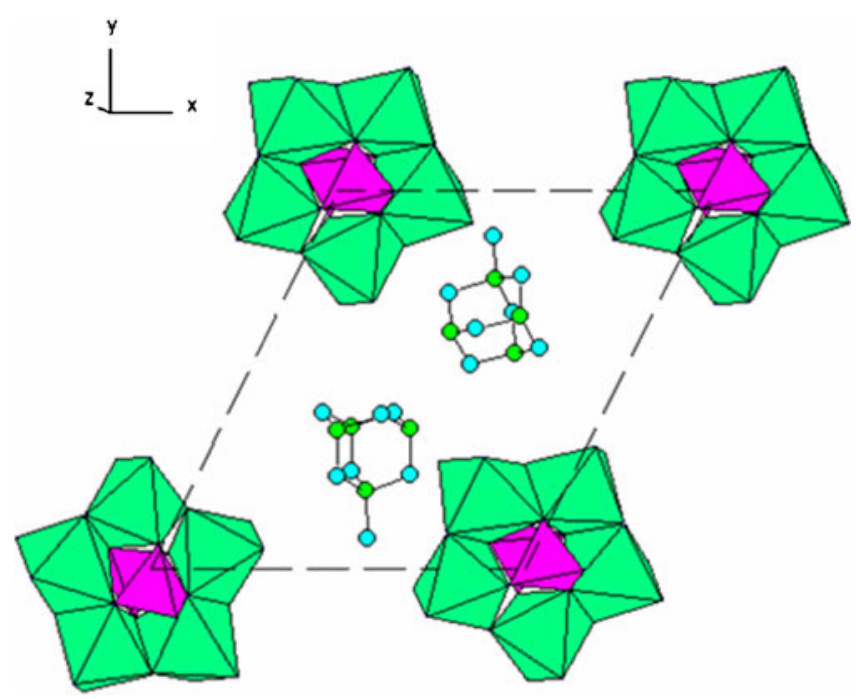

Figure 2. Me-HMTA forming packing with cluster through H-bonding in solid 2. 
The crystal structure of $\mathbf{2}$, [(HMTA- 3.2 Crystal structures of diamine derived $\mathrm{H}_{2} \mathrm{P}_{2} \mathrm{Mo}_{5}$ $\left.\mathrm{Me})_{2}\right]\left[\mathrm{H}_{4} \mathrm{P}_{2} \mathrm{Mo}_{5} \mathrm{O}_{23}\right] \cdot 6 \mathrm{H}_{2} \mathrm{O}$, is made of tetraprotonated cluster $\mathrm{H}_{4} \mathrm{P}_{2} \mathrm{Mo}_{5}$ and HMTA-Me (HMTA = Hexamethylenetetramine) cations with space-filling water molecules. In 2, C-H ‥ O (figure 2) interactions are responsible for seggregation of the cluster and organic cations. solids $(\mathbf{3}, \mathbf{4}$ and $\mathbf{5})$

3.2a Phase diagram of en-phosphomolybdate $-\mathrm{H}_{2} \mathrm{O}$ system: Crystallization was performed over the entire pH range (1-12) in the presence of en but different weak

Table 3. Experimental condition and type of tectons of solids 1-5.

\begin{tabular}{|c|c|c|c|}
\hline Sample code & Composition & Temperature/pH & Tectons \\
\hline 1 & {$\left[\left(\mathrm{C}_{4} \mathrm{H}_{10} \mathrm{NO}\right)_{5}\right]\left[\mathrm{HP}_{2} \mathrm{Mo}_{5} \mathrm{O}_{23}\right] .5 \mathrm{H}_{2} \mathrm{O}$} & $\mathrm{RT}, \mathrm{pH}=4$ & \\
\hline 2 & {$\left[(\mathrm{HMTA}-\mathrm{Me})_{2}\right]\left[\mathrm{H}_{4} \mathrm{P}_{2} \mathrm{Mo}_{5} \mathrm{O}_{23}\right] \cdot 6 \mathrm{H}_{2} \mathrm{O}$} & $\mathrm{RT}, \mathrm{pH}=4.2$ & \\
\hline 3 & $\left(e n \mathrm{H}_{2}\right)_{2}\left[\mathrm{H}_{2} \mathrm{P}_{2} \mathrm{Mo}_{5} \mathrm{O}_{23}\right]$ & $150^{\circ} \mathrm{C}, \mathrm{pH}=1$ & \\
\hline 4 & $\left(e n \mathrm{H}_{2}\right)_{2}(e n)_{0.5}\left[\mathrm{H}_{2} \mathrm{P}_{2} \mathrm{Mo}_{5} \mathrm{O}_{23}\right] .9 \mathrm{H}_{2} \mathrm{O}$ & $150^{\circ} \mathrm{C}, \mathrm{pH}=3$ & \\
\hline 5 & $\left(e n \mathrm{H}_{2}\right)(e n \mathrm{H})_{2}\left[\mathrm{H}_{2} \mathrm{P}_{2} \mathrm{Mo}_{5} \mathrm{O}_{23}\right] .3 \mathrm{H}_{2} \mathrm{O}$ & $150^{\circ} \mathrm{C}, \mathrm{pH}=5-7$ & \\
\hline
\end{tabular}


organic acids. Scheme 2 shows the formation of three types of products based on colour depending on the $\mathrm{pH}$ range. In the $\mathrm{pH}$ range $5-7$, the products were biphasic mixture containing white 5 and red $\mathbf{7}$ crystals.

At very low $\mathrm{pH}(\mathrm{pH}=1)$, an anhydrous solid $\mathbf{3}$, $\left(e n \mathrm{H}_{2}\right)_{2}\left[\mathrm{H}_{2} \mathrm{P}_{2} \mathrm{Mo}_{5} \mathrm{O}_{23}\right]$ was obtained. The crystal packing of 3 is made of two tectons, en $\mathrm{H}_{2}$ and $\mathrm{H}_{2} \mathrm{P}_{2} \mathrm{Mo}_{5}$ cluster (table 3). Adjacent clusters are bridged by a pair of $e n \mathrm{H}_{2}$ cations through strong $\mathrm{N}-\mathrm{H}$. .O interactions (figure 3) (supplementary table $\mathrm{S} 1$ ). The solid 4 , $\left(e n \mathrm{H}_{2}\right)_{2}(e n)_{0.5}\left[\mathrm{H}_{2} \mathrm{P}_{2} \mathrm{Mo}_{5} \mathrm{O}_{23}\right] \cdot 9 \mathrm{H}_{2} \mathrm{O}$ is another multicomponent crystal derived from $e n \mathrm{H}_{2}$ and $\mathrm{H}_{2} \mathrm{P}_{2} \mathrm{Mo}_{5}$ tectons. Also, water molecules mediate the building of this complex solid (figure 4). Analysis of colourless crystals isolated at $\mathrm{pH}=5-7$ indicated the presence of 5. The crystal structure of $\mathbf{5},\left(e n \mathrm{H}_{2}\right)(e n \mathrm{H})_{2}\left[\mathrm{H}_{2} \mathrm{P}_{2} \mathrm{Mo}_{5} \mathrm{O}_{23}\right]$. $3 \mathrm{H}_{2} \mathrm{O}$, consists of the diprotonated Strandberg cluster and two types of protonated ethylenediammonium cations. A significant structural feature is that of $\mathrm{P}_{2} \mathrm{Mo}_{5}$ cluster being linked into chains through mediating water molecules. The chains are further linked through diprotonated $e n \mathrm{H}_{2}$ forming 2-D sheets (figure $5 b$ ).

\subsection{Crystal structures of diamine derived $\mathrm{P}_{4} \mathrm{Mo}_{6}$ solids $(\mathbf{6}, 7,8$ and 9$)$}

Crystallization under hydrothermal condition at higher temperatures were favourable for the reduction of molybdenum(VI) to molybdenum(V) resulting in another fully reduced phosphomolybdate cluster, $\left\{\mathrm{P}_{4} \mathrm{Mo}_{6}^{\mathrm{V}} \mathrm{O}_{31}\right\}$.

Structural analysis of all the red crystals 6-8 showed the presence of $\left\{\mathrm{P}_{4} \mathrm{Mo}_{6}^{\mathrm{V}} \mathrm{O}_{31}\right\}$ clusters as one of the building blocks along with ethylenediammonium and sodium cations. We carried out bond

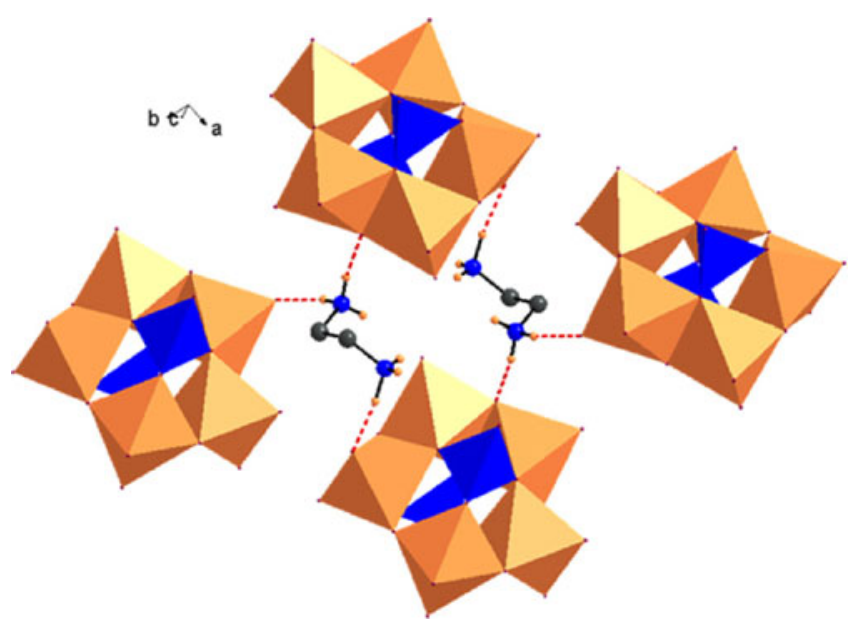

Figure 3. 2-D sheet of $\left(e n \mathrm{H}_{2}\right)_{2}\left[\mathrm{H}_{2} \mathrm{P}_{2} \mathrm{Mo}_{5} \mathrm{O}_{23}\right], 3$ through the H-bonding of N-H. . O-Mo.

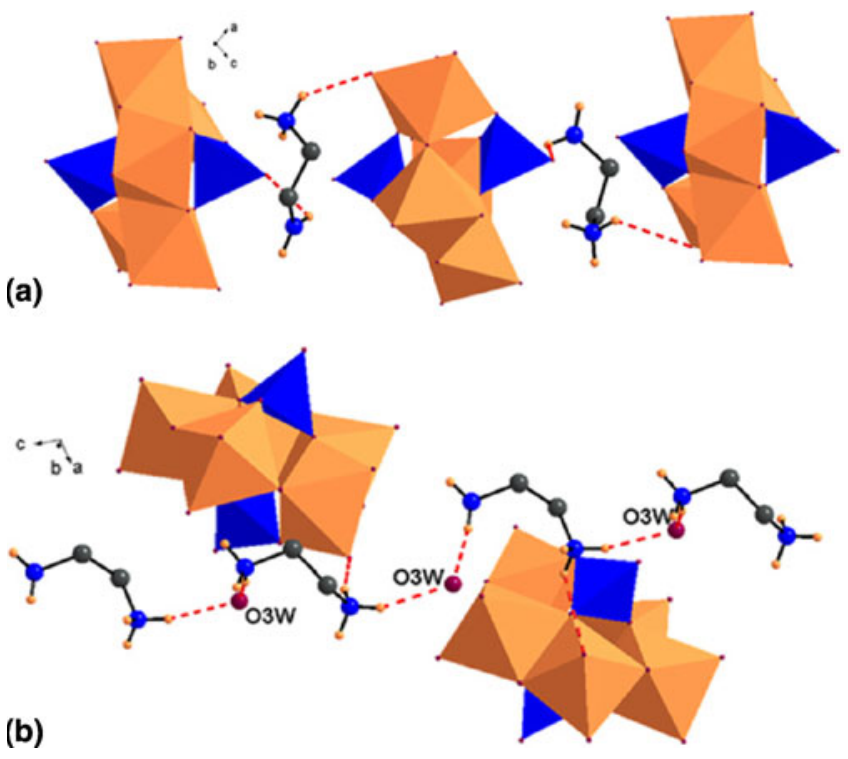

Figure 4. (a) $1-\mathrm{D}$ chain among $e n \mathrm{H}_{2}$ and $\mathrm{P}_{2} \mathrm{Mo}_{5} \mathrm{O}_{23}$ cluster through the H-bonding. (b) 1-D chain of $\mathbf{4}$ through the $\mathrm{H}$-bonding of $\left(e n \mathrm{H}_{2}\right) \mathrm{N}-\mathrm{H} \cdot \cdots \mathrm{Ow} \cdot \cdot \mathrm{H}-\mathrm{N}\left(e n \mathrm{H}_{2}\right)$ and $\left(e n \mathrm{H}_{2}\right)$ N-H. . O-Mo.

valence sums (BVS) to ascertain the nature of protonation of $e n$ and the clusters. BVS of $\mathbf{6}$ revealed six protonated $\mu_{2}-\mathrm{O}$ atoms and fourteen protonated terminal $\mathrm{P}-\mathrm{O}$ atoms. Hence, every cluster has six $\mathrm{Mo}_{5}(\mathrm{OH})_{3}$, one $\mathrm{PO}_{3}(\mathrm{OH})$ and three $\mathrm{P}(\mathrm{OH})_{2}$ units (table 4). Hence the composition of $\mathbf{6}$ was assigned to be $(e n)_{4}(e n \mathrm{H})_{3}\left[\mathrm{Na}\left\{\mathrm{H}_{10} \mathrm{P}_{4} \mathrm{Mo}_{6} \mathrm{O}_{31}\right\}_{2}\right] \cdot 12 \mathrm{H}_{2} \mathrm{O}$. This is in accordance with the cases of $\mathbf{7}$ and $\mathbf{8}$, where the $P_{4} M o_{6}$ units constituting a dimer have the same sites of protonation. The $\mathrm{Na}\left(\mathrm{P}_{4} \mathrm{Mo}_{6}\right)_{2}$ dimers are formed by crystallographically different Mo, $\mathrm{P}$ and $\mathrm{O}$ atoms. Unlike $\mathbf{7}$ and $\mathbf{8}$, where $\{\mathrm{A}-\mathrm{Na}(1)-\mathrm{A}\}$ type of dimers formed by crystallographically identical $\mathrm{P}_{4} \mathrm{Mo}_{6}$ clusters were observed, 6 consists of $\{\mathrm{A}-$ $\mathrm{Na}(1)-\mathrm{B}$ \} type of dimers (figure 6). Both solids 7, $\left(e n \mathrm{H}_{2}\right)(e n \mathrm{H})_{5} \mathrm{Na}_{2}\left[\mathrm{H}_{15}\left\{\mathrm{P}_{4} \mathrm{Mo}_{6} \mathrm{O}_{31}\right\}_{2}\left(\mathrm{H}_{2} \mathrm{O}\right)\right] .4 \mathrm{H}_{2} \mathrm{O}$ and 5 were found in the same reaction. The structure is a beautiful assembly of sodium bridged lower-valent phosphomolybdate cluster interacting through $\mathrm{Na}-\mathrm{O}-\mathrm{P}$ to form a 3-D structure (figure 7). BVS analysis of $\mathbf{8}$ suggested that three $\mu_{2}-\mathrm{O}$ atoms and five terminal $\mathrm{P}-$ $\mathrm{O}$ atoms are protonated. The composition of the solid was deduced as $(e n \mathrm{H})_{7}\left[\mathrm{Na}\left\{\mathrm{H}_{8} \mathrm{P}_{4} \mathrm{Mo}_{6} \mathrm{O}_{31}\right\}_{2}\right] .8 \mathrm{H}_{2} \mathrm{O}$. Two $\mathrm{P}_{4} \mathrm{Mo}_{6}$ clusters are linked through six $\mu_{2}-\mathrm{O}$ atoms $[\mathrm{O}(1), \mathrm{O}(2), \mathrm{O}(4)]$ to $\mathrm{Na}(1)$ cations to form $\left[\mathrm{Na}(1)\left(\mathrm{P}_{4} \mathrm{Mo}_{6}\right)\right]_{2}$ dimer (figure 8$)$. The octahedral coordination around $\mathrm{Na}(2)$ is completed by two water molecules. Strong H-bonding interactions (supplementary table $\mathrm{S} 1$ ) involving cluster anions, $e n \mathrm{H}_{2}$ and water molecules occur in the structure. Although both 7 and 


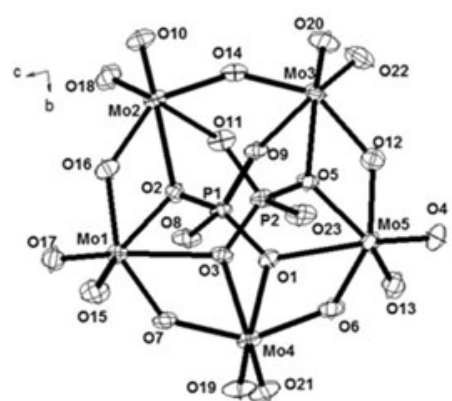

(a)



(b)

Figure 5. (a) ORTEP view of cluster $P_{2} \mathrm{Mo}_{5}$ in 5. Thermal ellipsoids are drawn at $50 \%$ probability level. (b) 2-D sheet of $\left(e n \mathrm{H}_{2}\right)(e n \mathrm{H})_{2}\left[\mathrm{H}_{2} \mathrm{P}_{2} \mathrm{Mo}_{5} \mathrm{O}_{23}\right] \cdot 3 \mathrm{H}_{2} \mathrm{O}, 5$ through the hydrogen bonding of Ow-H. . O-Mo, N-H. . O-Mo and N-H . . O-P.

Table 4. Experimental condition and type of tectons of solids 6-10.

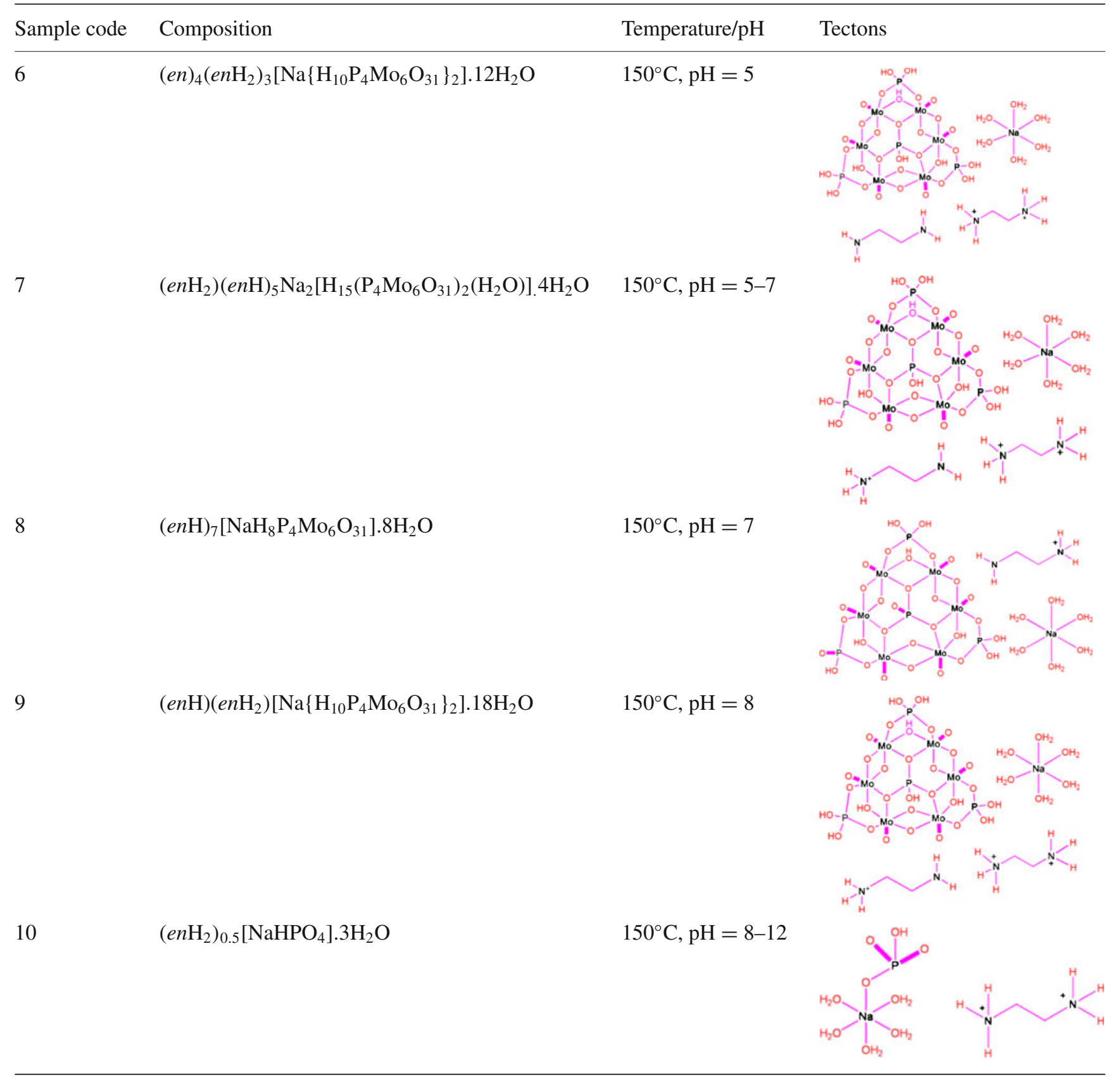




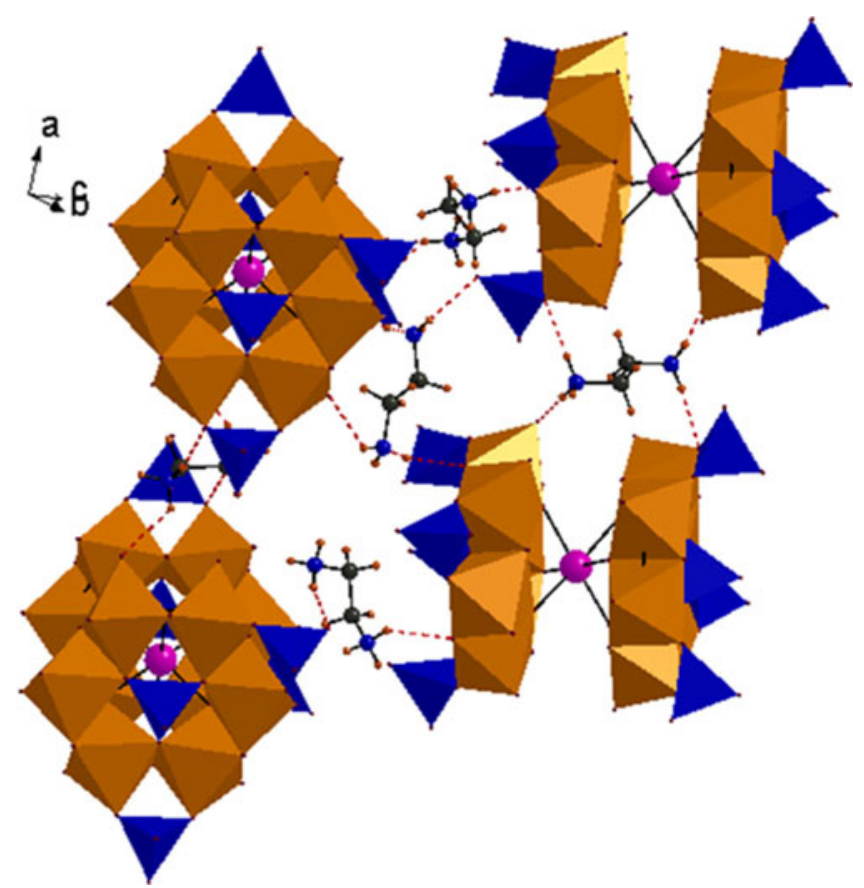

Figure 6. H-bonding occurring between the dimeric anions and organic cations in $\mathbf{6}$. Water molecules are omitted for clarity.

8 are based on $\mathrm{Na}\left(\mathrm{P}_{4} \mathrm{Mo}_{6}\right)_{2}$ dimeric unit, the two structures differ considerably. While in 7, two kinds of dimers, $\left[\mathrm{Na}(1)\left(\mathrm{P}_{4} \mathrm{Mo}_{6}\right)\right]_{2}$ and $\left[\mathrm{Na}(2)\left(\mathrm{P}_{4} \mathrm{Mo}_{6}\right)\right]_{2}$, differing in protonation were observed while in $\mathbf{8}$ only one type occurred. In this context, $\left[\mathrm{Na}(1)\left(\mathrm{P}_{4} \mathrm{Mo}_{6}\right)\right]_{2}$ dimer occurring in $\mathbf{8}$ was similar to $\left[\mathrm{Na}(2)\left(\mathrm{P}_{4} \mathrm{Mo}_{6}\right)\right]_{2}$ observed in 7 containing the same number of protonated atoms. In addition, 7 possesses a layered structure, $\mathbf{8}$ consists of $1-\mathrm{D}$ chains of $\mathrm{Na}\left(\mathrm{P}_{4} \mathrm{Mo}_{6}\right)_{2}$ dimers. In contrast to almost orthogonal disposition of dimeric units in $\mathbf{7}$, a unidirectional alignment of such units was encountered in $\mathbf{8}$.

At $\mathrm{pH}$ 8, another solid containing $\mathrm{P}_{4} \mathrm{Mo}_{6}$ cluster, $(e n \mathrm{H})\left(e n \mathrm{H}_{2}\right)\left[\mathrm{Na}\left\{\mathrm{H}_{10} \mathrm{P}_{4} \mathrm{Mo}_{6} \mathrm{O}_{31}\right\}_{2}\right] \cdot 18 \mathrm{H}_{2} \mathrm{O}(\mathbf{9})$ was isolated. This structure showed the largest unit cell obtained in our system. The compound 9 consists of $P_{4} M o_{6}$ cluster with three $\mathrm{P}(\mathrm{OH})_{2}$ and one $\mathrm{PO}_{3}(\mathrm{OH})$ group along with three $\mu_{2}-\mathrm{OH}$ units. Such protonation has been encountered in 7 but here the clusters have been linked through $\mathrm{Na}^{+}$to form $\{\mathrm{A}-\mathrm{Na}-\mathrm{A}\}$ dimer
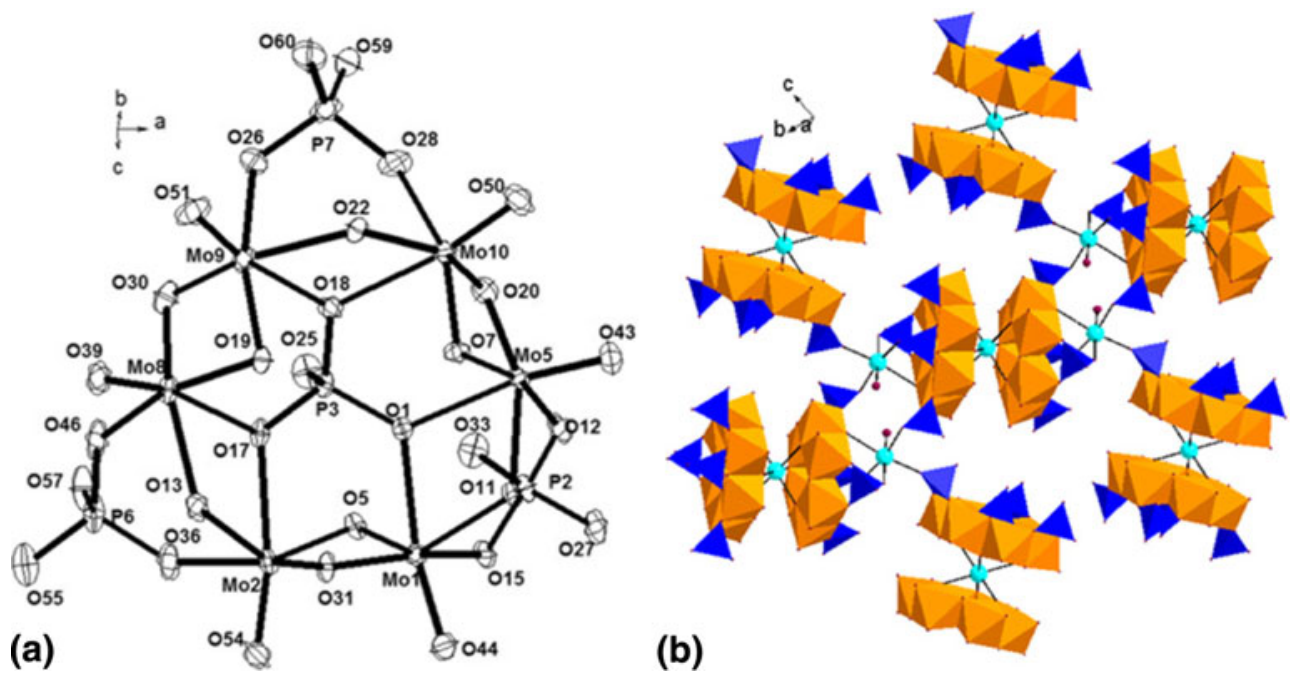

Figure 7. (a) ORTEP view of cluster $P_{4} \mathrm{Mo}_{6}$ in 7. Thermal ellipsoids are drawn at $50 \%$ probability level. (b) View of channels along [001]. The organic cations and water molecules have been omitted for clarity. 


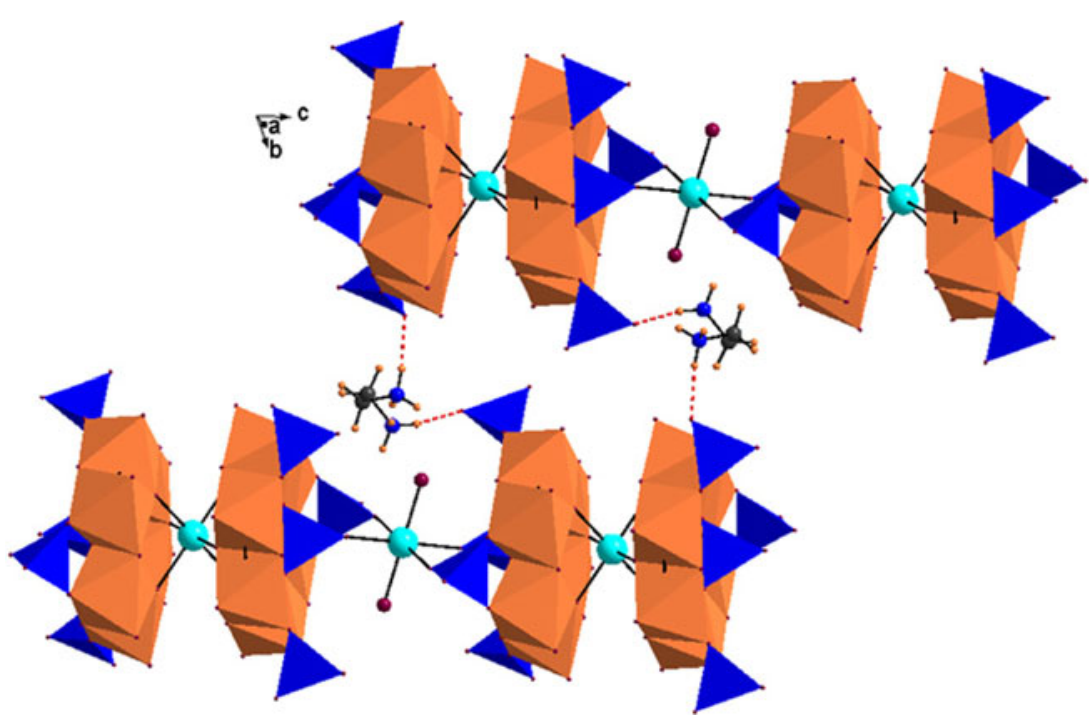

Figure 8. $\mathrm{Na}\left[\mathrm{P}_{4} \mathrm{Mo}_{6}\right]_{2}$ dimer linking two $P_{4} \mathrm{Mo}_{6}$ units connected through $\mathrm{NaO}_{6}$ octahedra and $\mathrm{P}-\mathrm{O} \cdots \mathrm{H}-\mathrm{N}(e n \mathrm{H})$ forming $2-\mathrm{D}$ chains in $\mathbf{8}$.

rather than $\{\mathrm{A}-\mathrm{Na}-\mathrm{B}\}$ type. The dimers are arranged in an orthogonal mode with respect to the nearest neighbour. In addition to the organic cations and water molecules, a tetrahedral phosphate group also exists in the structure. The structure exhibits complex $\mathrm{H}$ bonding interactions (supplementary table S1) involving



(a)

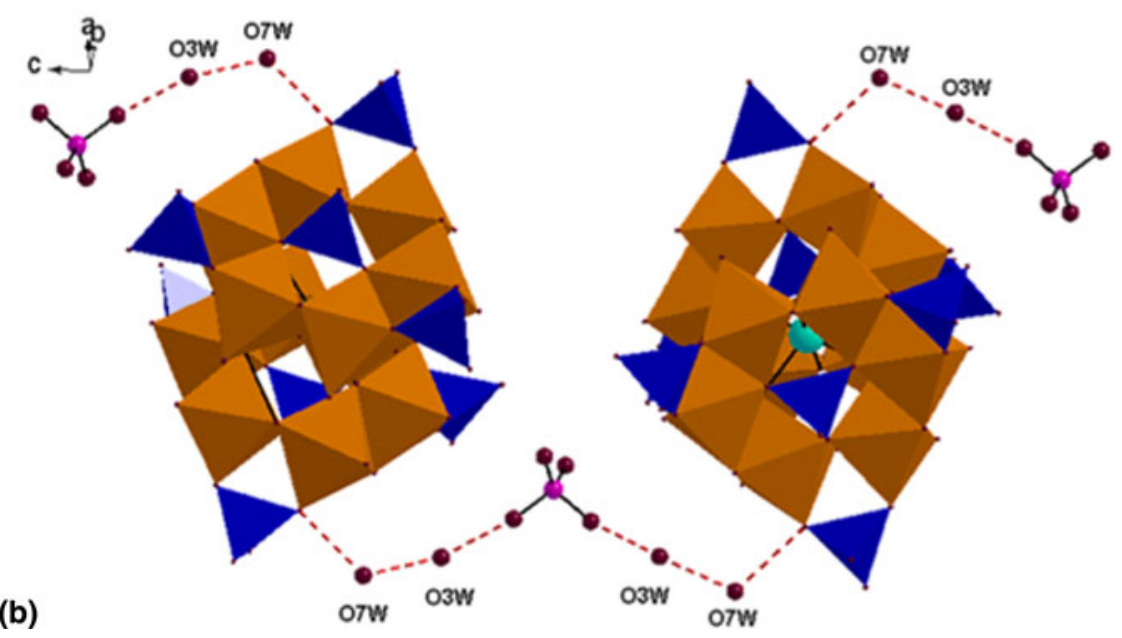

Figure 9. (a) 1-D chain form through the $\mathrm{P}-\mathrm{O} \ldots \mathrm{Ow} \cdots \mathrm{O}-\mathrm{P}$ interactions in solid 9. (b) Zig-zag chain is form through $\mathrm{PO}_{4}$ and water interactions with cluster. 


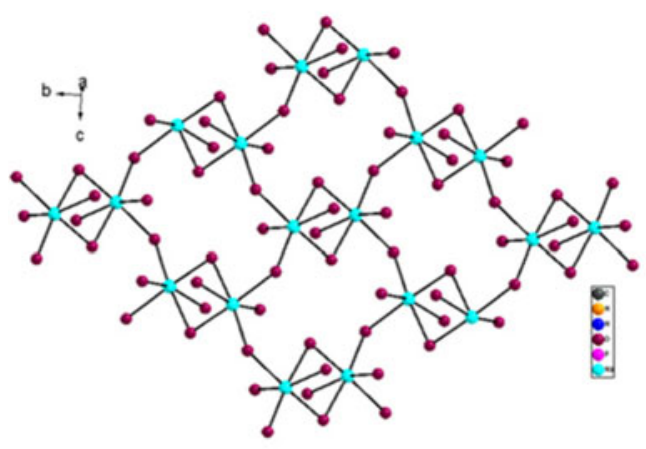

(a)

Figure 10. (a) 2-D sheets of hydrated Na water bridge dimer in 10. (b) 2-D sheet through the $\mathrm{N}-\mathrm{H}$. . O-P and P-H. . O-P interaction in $\mathbf{1 0}$.

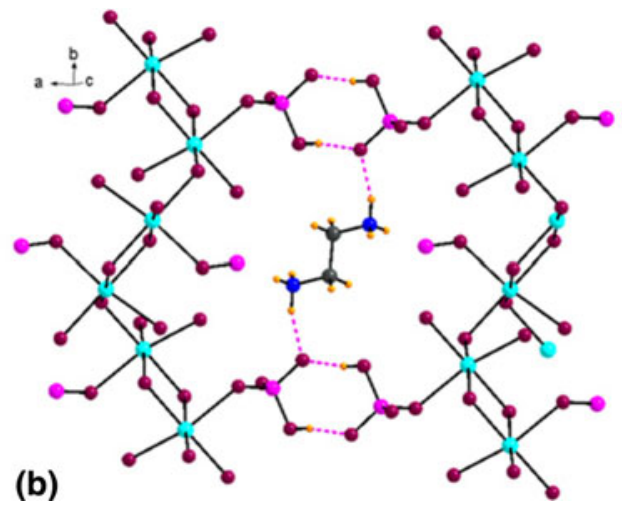

the anionic dimers, organic cations, water molecules and phosphate group (figure 9).

Under strong alkaline conditions $(\mathrm{pH}>8)$ long, white needle-shaped crystals of $\left(e n \mathrm{H}_{2}\right)_{0.5}\left[\mathrm{NaHPO}_{4}\right] .3 \mathrm{H}_{2} \mathrm{O}$, 10 were isolated. The solid is an unusual salt of ethylenediammonium incorporated sodium hydrogen phosphate. Retrosynthesis of $\mathbf{1 0}$ suggested that the beautiful assembly is built from the condensation of the tectons, a water-bridged dimer $\left\{\mathrm{Na}_{2}\left(\mathrm{H}_{2} \mathrm{O}\right)_{10}\right\}$ and monoprotonated phosphate, $\left\{\mathrm{HPO}_{4}\right\}$ (table 4). The condensation on $b c$-plane led to the interaction of sodium hydrate dimers to form a 2-D sheet of the composition $\left\{\mathrm{Na}\left(\mathrm{H}_{2} \mathrm{O}\right)_{3}\left(\mathrm{HPO}_{4}\right)\right\}^{-}$. The dimers are linked to each other through water bridges. The sheets are connected to each other through the complementary interactions (supplementary table $\mathrm{S} 1$ ), $\mathrm{P}-\mathrm{H}$. . O O-P as shown in figure 10 . The counter cations $e n \mathrm{H}_{2}$ occurs in the cavities and connect the monophosphates through $\mathrm{N}-\mathrm{H} \cdots \mathrm{O}$ (figure 10b).

\section{Analysis of molybdenum phosphate hybrid solids}

The FTIR spectra observed for $\mathbf{1}$ and $\mathbf{2}$ associated with $\mathrm{Mo}_{5}$ ring were similar. The strong intensity bands at $950,900,875$ and $850 \mathrm{~cm}^{-1}$ are due to $v_{\mathrm{Mo}=\mathrm{O}}$ for the different molybdenum environments. The features at 750 , 700,600 and $530 \mathrm{~cm}^{-1}$ are attributed to the symmetric and asymmetric stretching modes of the molybdate ring, $\mathrm{Mo}_{5} \mathrm{O}_{15}$, while a band $\sim 1040 \mathrm{~cm}^{-1}$ is due to the terminal $\mathrm{P}-\mathrm{O}$ of the capped phosphate sites. The bands at 3020, 2880, 2500, 1650, 1500, 1340 and $1100 \mathrm{~cm}^{-1}$ and $3177,1634,1465,1400,1260,1150$ and $1100 \mathrm{~cm}^{-1}$ are in the characteristic region of the organic groups of the compounds $\mathbf{1}$ and $\mathbf{2}$, respectively. The solids from 3-10 have been characterized by various analytical techniques. FTIR spectra of compounds exhibit a strong band at $952 \mathrm{~cm}^{-1}$, characteristic of $v(\mathrm{M}=\mathrm{O})$ and features at 733 and $1038 \mathrm{~cm}^{-1}$ associated with $v(\mathrm{Mo}-\mathrm{O}-\mathrm{Mo})$ and $v(\mathrm{P}-\mathrm{O})$, respectively. The features at 3493,3026 and $1522 \mathrm{~cm}^{-1}$ are characteristic of $e n \mathrm{H}_{2}$, while other strong features at 3368 and $1577 \mathrm{~cm}^{-1}$ are assigned to water molecules.

\section{Chemistry of formation of phosphomolybdate cluster-based solids}

In this study, we have isolated several new crystals based on phosphomolybdate clusters. A detailed investigation of the system was carried out where synthesis was carried out in the presence of three different organic acids viz. oxalic acid, succinic acid and glycine (an amino acid) in the entire $\mathrm{pH}$ range (1-12). Although organic acids were not incorporated in the structure of solids, they appear to influence the crystallization. A combination of powder and single crystal XRD clearly establishes that only a few solids crystallize under varying $\mathrm{pH}$. The present investigation unambiguously proved that a combination of en along with a suitable $\mathrm{pH}$ and temperature is essential to obtain the reduced cluster $\left\{\mathrm{P}_{4} \mathrm{Mo}_{6}^{V} \mathrm{O}_{31}\right\}$. The cluster $\left\{P_{4} M o_{6}\right\}$ is a very stable species that is formed under a myriad of synthetic conditions and is the basis of numerous and diverse group of phosphomolybdates. ${ }^{22}$ The cluster has not been observed in the absence of metal cations. It is significant that in most of the structures, dimerization occurs through linking with a transition metal ion and solids based on exclusively linkage with sodium ion are rare. In this context, the present work is a significant contribution where $\left\{P_{4} M o_{6}\right\}$ dimers linked with sodium cation led to the isolation of structures with varying dimensionality. It is noteworthy that when the reactions were performed in the presence of the three selected organic acids (viz. succinic acid, oxalic acid and glycine) under ambient conditions, reduction of molybdenum core was not effected 
at any $\mathrm{pH}$. This observation establishes that temperature (indirectly hydrothermal condition) is critical to form reduced phosphomolybdates.

\section{Conclusions}

The system of reduced phosphomolybdates was investigated extensively under hydrothermal conditions. Three $\mathrm{P}_{2} \mathrm{Mo}_{5}$, four $\mathrm{Na}\left(\mathrm{Mo}_{6} \mathrm{P}_{4}\right)_{2}$ and $\mathrm{NaHPO}_{4}$ based solids were obtained by varying $\mathrm{pH}$ as well as organic template (succinic acid, oxalic acid and glycine). The dimensionality of phosphomolybdates framework was found to be controllable to a considerable extent by reaction parameters such as $\mathrm{pH}$ and organic template. This confirms the strong ability of hydrothermal technique for the preparation of new organic-inorganic hybrid materials.

\section{Supplementary material}

For supplementary information (table S1), see www.ias. ac.in/chemsci website.

\section{Acknowledgements}

DK acknowledges the Department of Science and Technology (DST), New Delhi for Research Fellowship. AR acknowledges the DST for providing continuous funding for the past two decades and infrastructural support.

\section{References}

1. Singh M and Ramanan A 2011 Cryst. Growth Des. 11 3381; (b) Singh M, Loftland S E, Ramanujachary K V and Ramanan A 2011 Cryst. Growth Des. 105105

2. Dolbecq A, Dumas E, Mayer C R and Mialane P 2010 Chem. Rev. 1106009

3. Müller A, Peters F, Pope M T and Gatteschi D 1998 Chem. Rev. 98239

4. (a) Pope M T and Müller A 1994 Polyoxometalates: From platonic solids to anti-retroviral activity (Dordrecht: Kluwer Academic Publishers); (b) Cindriæ M, Veksli Z and Kamenar B 2009 Croat. Chem. Acta 82 345; (c) Yamase T 1993 Mol. Eng. 3 241; (d) Kortza U, Müller A, Slageren J V, Schnacke J, Dalal N S and Dressel M 2009 Coord. Chem. Rev. 2532315

5. (a) Thomas J and Ramanan A 2008 Cryst. Growth Des. 8 3390; (b) Upreti S and Ramanan A 2005 Acta Cryst. E61 m414; (c) Upreti S and Ramanan A 2008 Synth. React. Inorg., Met.-Org., Nano-Met. Chem. 38 69; (d) Upreti S and Ramanan A 2006 Cryst. Growth Des. 6 2066; (e) Thomas J and Ramanan A 2011 Inorg. Chim. Acta 372 243
6. Bareyt S, Piligkos S, Hasenknopf B, Gouzerh P, Lacôte E, Thorimbert S and Malacria M 2005 J. Am. Chem. Soc. 1276788

7. Niu J Y, Guo D J, Wang J P and Zhao J W 2004 Cryst. Growth Des. 424

8. Zheng P Q, Ren Y P, Long L S, Huang R B and Zheng L S 2005 Inorg. Chem. 441190

9. Ren Y P, Kong X J, Long L S, Huang R B and Zheng L S 2006 Cryst. Growth Des. 6572

10. Ren Y P, Kong X J, Hu X Y, Sun M, Long L S, Huang R B and Zheng L S 2006 Inorg. Chem. 454016

11. Dey C, Kundu T and Banerjee R 2012 Chem. Commun. 48266

12. Desiraju G R, Vittal J J and Ramanan A 2011 Crystal engineering - A textbook (Singapore: World Scientific Press)

13. Desiraju G R 2007 Angew. Chem. 468342

14. (a) Singh M, Thomas J and Ramanan A 2010 Aust. J. Chem. 63 1; (b) Pavani K, Singh M and Ramanan A 2011 Aust. J. Chem. 64 68; (c) Singh M, Kumar D, Thomas J and Ramanan A 2010 J. Chem. Sci. 122757

15. Tectons (the Greek word $\tau \varepsilon \kappa \tau \omega \nu$ for builder) are chemically reasonable molecules that induce supramolecular aggregation through controlled geometry. These vary from simple molecules such as $\mathrm{H}_{2} \mathrm{O}$ to robust units such as metal complexes; (a) Nangia A 2004 Nomenclature in crystal engineering in encyclopedia of supramolecular chemistry (United Kingdom: CRC Press); (b) Brunet P, Michel S and Wuest J D 1997 J. Am. Chem. Soc. 119 2737

16. (a) Pavani K, Singh M, Ramanan A, Lofland S E and Ramanujachary K V2009 J. Mol. Struct. 933 156; (b) Pavani K and Ramanan A 2005 Eur. J. Inorg. Chem. 3080; (c) Thomas J, Agarwal M, Ramanan A, Chernova $\mathrm{N}$ and Whittingham M S 2009 Cryst. Eng. Commun. 11 625; (d) Upreti S, Datta A and Ramanan A 2007 Cryst. Growth Des. 7966

17. (a) He X, Zhang P, Song T-U, Mu Z-C, Yu J-H, Wang Y and Xu J-N 2004 Polyhedron 23 2153; (b) Burkholder E, Golub V, O'Connor C J, and Zubieta J 2003 Inorg. Chem. 42 6729; (c) Lu J, Xu Y, K N, Goh and Chia L S 1998 Chem. Commun. 2733; (d) Meng J X, Lu Y, Li Y G, Fu H and Wang E B, 2011 Cryst. Eng. Commun. 132479

18. Bruker Analytical X-ray Systems 2000 SMART: Bruker molecular analysis research tool, Version 5.618

19. Bruker Analytical X-ray Systems 2001 SAINT-NT, Version 6.04

20. Bruker Analytical X-ray Systems 2000 SHELXTL-NT, Version 6.10

21. Klaus B 1999 DIAMOND, Version 1.2c (Germany: University of Bonn)

22. Zhang L, Li X, Zhou Y and Wang X 2009 J. Mol. Struct. 928 59; (b) Khan M I, Chen Q and Zubieta J 1995 Inorg. Chim. Acta 235 135; (c) Ma Y, Li Y, Wang E, Lu Y, Wang X and Xu X 2007 J. Coord. Chem. 60 719; (d) Streb C, Long D L and Cronin L 2007 Chem. Commun. 471; (e) Streb C, Long D L and Cronin L 2006 Cryst. Eng. Commun. 8 629; (f) Xu L, Sun Y, Wang E, Shen E, Liu Z, Hu C, Xing Y, Lin Y and Jia H 1999 J. Solid State Chem. 146533 